\title{
La concesión del título de (I) conde de Buendía por el rey Alfonso XII de Castilla (1465) como expresión del poder del linaje Acuña
}

\section{The granting of count of (I) Buendía title by the king Alfonso XII of Castille (1465) as the expression of Acuña lineage power}

\author{
Dolores Carmen Morales MuñIz \\ UNED (C. A. MADRID)
}

A mis amigos Vicenta $M^{a}$ Márquez de la Plata y Luis Valero de Bernabé, nobles en todos los sentidos.

\section{RESUMEN}

La concesión del título de I conde de Buendía por el rey Alfonso XII de Castilla permite analizar una doble realidad en un contexto de dualidad monárquica (1465-

68). Primerante remite a la importancia del linaje Acuña beneficiario de la merced en la persona de Pedro de Acuña. La concesión demuestra la condición de monarca del joven Alfonso: sólo el rey puede expedir títulos nobiliarios. El hecho

de que más adelante, la reina Isabel confirme el acto, ratifica la condición de su hermano como legítimo rey.

\section{PALABRAS CLAVE}

Título nobiliario, Buendía, linaje Acuña, conde/condado, poder nobiliario, monarquía dual, legitimidad de Alfonso XII.

\section{ABSTRACT}

The granting, on the part of the king of Castille Alfonso XII of the title of count of Buendía allows for an analysis of the double reality that from 1465 to 1468 existed in the context of a dual monarchy. The grant stressed the relevance of the Acuña lineage favored in the person of Pedro de Acuña. But of far larger relevance, the title likewise evidences the condition of king that young Alfonso had at the time as only the monarch could grant nobility titles. The ratification of that concession later on by queen Isabella I further santioned her brother's legitimacy as king.

\section{KEY WORDS}

Nobility title, Buendía, Acuña lineage, count/county, nobility power, dual monarchy, legitimacy of Alfonso XII. 
El rey Alfonso XII —hermano de la futura reina Isabel I—gobernó en Castilla paralelamente con su hermanastro Enrique IV durante los años 1465-68. Aunque su figura y su época ha sido intensamente tratada por mí a lo largo de sucesivas publicaciones, algunos de los aspectos de su reinado siguen abiertos a futuras investigaciones. ${ }^{1}$

En el presente trabajo vamos a analizar la concesión del único título nobiliario que el rey Alfonso concedió en su corto reinado. Título que nos permitirá reflexionar, siempre como expresión de un acto tan soberano como cualquier otra regalía, sobre dos cuestiones diferentes. Una de ellas remite al acto de concesión en sí y la significación de un título nobiliario. Otra nos lleva a ocuparnos de su beneficiario y lo que dicha concesión implica para su linaje, en este caso, para Pedro de Acuña, señor de Buendía. Y siempre subrayando como la concesión del título enlaza con el poder político de la nobleza, tema este que ha reclamado mucha atención y de forma continuada y reciente ${ }^{2}$

\section{LOS TÍTULOS NOBILIARIOS: CARACTERÍSTICAS Y SIGNIFICACIÓN}

La concesión de títulos nobiliarios es un aspecto poco estudiado aun cuando se trata de un aspecto asociado a la propia condición nobiliaria, tema este último

\footnotetext{
1 Todos los trabajos — diez-sobre Alfonso publicados hasta 1996 están reseñados en las notas 1. y 2. del trabajo, «Significación e Historiografía de Alfonso XII de Castilla: nuevas vías de investigación», Medievalismo, 6 (1996), pp. 213-217. Desde entonces se han publicado tres trabajos más, a saber, «Don Alfonso ¿Príncipe de Asturias?» en las Actas del Congreso sobre Los Orígenes del Principado de Asturias y de la Junta General, Oviedo, 1998, pp. 207-227, «El origen de la Inquisición en los reinados de Enrique IV y Alfonso XII de Castilla (1454-1474)» Autour de L'Inquisition. Etudes sur le Saint-Office, Université de Picardie Jules Verne.París, Indigo \& Côté-femmes éditions, 2002, y «El difícil camino de la princesa Isabel de Castilla hacia el trono: 1468-1474». Jornadas sobre La España de Isabel La Católica, Centro Asociado de Córdoba a la UNED, Córdoba, 2005, pp. 72-94. También he considerado la cuestión alfonsina en dos ocasiones más: En noviembre de 2003 en el Simposio Isabel de Castilla y América: La Reina Isabel y su Corte. Isabel la Católica y Cristóbal Colón. Centro Regional de la UNED de Palencia. 14 y 15 de noviembre de 2003, ponencia con el título «La familia de la reina: el príncipe-rey Don Alfonso». Invitada por el Colegio Heráldico de España y de las Indias «Cátedra Marqués de Ciadoncha», en las XI Jornadas Superiores, en el ciclo sobre «Sombras y Luces del reinado de Isabel La Católica», pronuncié la conferencia impartida el 8 de junio de 2004, con el título «Los conflictos dinásticos: Isabel en sus relaciones con sus hermanos: Alfonso y Enrique» donde traté otros aspectos, no considerados hasta el momento, de los tres hermanos hijos de Juan II y que fueron los tres reyes. Alfonso no ha sido tratado de forma monográfica más que por mí salvo excepcionalmente y generalmente por estudios paleográficos. Es magnífico el trabajo de O. PEREA RodRíGuEZ, «La Corte Literaria de Alfonso El Inocente (1465-1468) según las «Coplas a una Partida» de Guevara, poeta del «Cancionero General» en Medievalismo. Boletín de la Sociedad Española de Estudios Medievales, 11 (2001), pp. 33-57 en donde analiza un aspecto inédito del reinado de Alfonso que demuestra las muchas posibilidades que ofrece aun el personaje y la época.

${ }^{2}$ De entre la ingente bibliografía dedicada al tema destaca, por su reciente aparición, M.C QUINTANILLA RASO (Dir), «La nobleza titulada en la sociedad política de la Castilla bajomedieval» en Títulos, Grandes del reino y grandeza en la Sociedad politica fundamentos en la Castilla medieval, Madrid, Silex, 2006, pp. 17-87.
} 
muy cultivado. ${ }^{3}$ De entre las características propias de dicha condición destaca la perpetuidad, que es consustancial a la nobleza, es decir, una vez adquirida esta se conserva durante toda la vida sin necesidad de ningún otro pronunciamiento y $\sin$ posibilidad alguna de que pudiera ser cancelada por el soberano. Es una afirmación frecuente entre los especialistas la de subrayar que el rey podía privar de la vida a sus súbditos rebeldes pero nunca de su nobleza. Las formas de acceder o adquirir la nobleza, siguiendo a Las Partidas entre otras fuentes, remiten al linaje, mérito, cargo o sabiduría (esfuerzo intelectual). Ennoblecer era facultad exclusiva del rey : los reyes pueden conceder una merced nobiliaria graciosamente y sin ninguna limitación a quien lo consideraran conveniente y por las causas que estimasen oportunas.

La condición nobiliaria se sustentaba en una serie de valores y atributos consustanciales a la misma a través de los cuales se afianzaba y manifestaba externamente frente a la sociedad: linaje, solar, apellido, blasón y mayorazgo. El primero de los atributos remitía al conjunto de consanguíneos de un tronco común, constituyendo la comunidad de intereses, afectos y tradiciones con obligaciones y estricto código de valores que debía respetarse. El linaje era el receptor del pasado familiar en donde se mantenía vivo el culto a los antepasados, ostentando la autoridad el pariente mayor poseedor del patrimonio familiar a través de la institución del mayorazgo. Epicentro de valores como la solidaridad, el linaje también remitía a la notoriedad, esto es, la aceptación social del individuo condicionada por la de su propio linaje, denominándose notorio aquel, en el que, según se recoje en las ejecutorias de hidalguía, todos sus miembros siempre habían sido tenidos como hidalgos notorios. La condición nobiliaria se expresaba asimismo a través del solar, el apellido, el blasón, el mayorazgo, y, sobre todo el señorío, esto es, la privatización de un poder jurisdiccional sobre un determinado territorio o villa cuyos moradores quedaban sujetos a la autoridad del señor jurisdiccional obligados a prestaciones económicas y personales. El señorío era la culminación de todos los linajes, ya que sólo así se obtenía presencia dentro del estamento convirtiéndose en señores de vasallos. El paso siguiente era convertir el señor en un título del reino, transformando el señorío en un estado nobiliario. Al recibir el título del reino, el primer titular del mismo recibía simultáneamente la nobleza transmisible a sus des-

\footnotetext{
${ }^{3}$ El análisis sobre la concesión de títulos nobiliarios cuenta con más tradición en la Corona de Aragón que en la de Castilla. Así F. DE Moxó y Montolıú escribió para Anales de la Universidad de Alicante, "Jaime II y la nueva concesión de títulos nobiliarios en la España del s. XIV», (9), 1992, pp. 133-43, y también «El florecimiento de títulos en las Coronas de Aragón y Castilla en el siglo XIV», conferencia pronunciada y publicada en Barcelona en el Real Cuerpo de la Nobleza de Cataluña, Fundación Cultural de la nobleza española, en 1999. A. DE FLUVIA Escorsa ha escrito «Los títulos nobiliarios en el Principado de Cataluña s. IX-1716», para Hidalguía, 1988, 36 (207) pp. 249-255. Pero son, sobre todo, los genealogistas, heraldistas y especialistas en nobiliaria los que se han ocupado del tema L.VALERO DE BERNABÉ Y V.M.MÁRQUEZ DE LA PLATA, Nobiliaria española. Origen, evolución, instituciones y probanzas, Madrid, Prensa y Ediciones Iberoamericanas, 1996, también autores de un interesante y práctico trabajo, El Libro de Oro de los Duques, Madrid, Prensa y Ediciones Iberoamericanas, 1994.
} 
cendientes la cual se consolidaría la nobleza de sangre del linaje creado por dicho titular. $^{4}$

El título nobiliario era una distinción honorífica concedida por el soberano a un cierto titular con carácter perpetuo en premio a los servicios prestados a la Corona y con la facultad de transmitirlo a sus descendientes. La posesión de un título del reinado significaba la ascensión del último peldaño en el proceso de caracterización de un linaje. La transmisibilidad ininterrumpida, generación tras generación, por vía de varón, a todos los descendientes legítimos sin que esta pudiera ser limitada, condicionada ni obstaculizada en forma alguna por el soberano era característica esencial en la concesión de un título nobiliario. El título era asimismo irrevocable: puede extinguirse o privarse de la merced a quien no cumpla noblemente pero no puede privarse de aquel a sus descendientes legítimos pues rige el principio que nadie puede perjudicar a otro en su justo derecho. El título era, asimismo, gratuito, una merced otorgada sin contraprestación por parte del que la recibe aunque en la práctica se cree para premiar servicios distinguidos, o méritos tanto pasados como -y para el caso que nos ocupará es así- por venir.

El título era, en definitiva, una merced que hacía el rey a una persona para honrar en él a su linaje, una forma clara de reafirmar aquel, ascendiendo de la simple nobleza a la nobleza titulada que es la cúspide del estamento nobiliario. Y es, dentro de linaje, donde toma lugar el hecho sucesorio. A través de la concesión de un título se distingue, no sólo a una persona sino al linaje que tendrá un ejemplo a seguir en su primer poseedor. Un título no era enajenable sino que pertenecía a los bienes intangibles como la honra o la fama, siendo el primero su único poseedor, todos los demás lo hacen en lugar y representación del primer aquel. Naturalmente los títulos, muestra de ascenso social dentro de la jerárquica pirámide de la nobleza, eran muy ambicionados por los nobles, contribuyendo a reforzar el principio sucesorio de primogenitura existente en los linajes pues eran los primogénitos quienes los heredaban

\section{LOS ACUÑA: UN LINAJE PORTUGUÉS EN CASTILLA}

\section{El primer matrimonio de Martín Vázquez de Acuña. Los Pacheco-Girón y los títulos de marqués de Villena y conde de Urueña}

El linaje de origen portugués de los Acuña ${ }^{5}$ tiene a su primer protagonista en los hermanos Martín y Lope Vásques de Acuña, hijos de Vasco Martines de Acuña,

\footnotetext{
${ }^{4}$ Hemos seguido a V.M. Márquez de la Plata y L. Valero de Bernabé en la obra citada Nobiliaria..

${ }^{5}$ En prensa para el Diccionario Biográfico de la Real Academia de la Historia, he redactado diecinueve biografías pertenecientes a las diferentes ramas del linaje Acuña comenzando por Martín de Acuña, I conde de Valencia de Don Juan y los descendientes de esta rama de su segundo matrimonio, esto es, los siguientes tres condes de ese título: Pedro, Juan y Enrique. De la rama Téllez Girón- Pacheco, descendientes del primer matrimonio de Martín Vázquez, he redactado la biografía de su hijo Alonso Té-
} 
VI señor de Taboa, y de Beatriz Suárez de Albergaría. Martín Vasques —castellanizado Vázquez - de Acuña fue uno de los nobles portugueses que, junto con su familia, emigraron a Castilla a finales del siglo XIV. Con su primera mujer, Teresa Téllez Girón, tuvo catorce hijos. De entre todos - Luis, Teresa, Leonor, Beatriz, Ginebra, Isabel....- destacó Alfonso Téllez Girón, I Señor de Belmonte, el cual, para evitar que se perdiera el apellido de su madre, tomó las armas de los Girón. Casado con María Pacheco, tuvo dos descendientes - Juan Pacheco, marqués de Villena y Pedro Girón, maestre de Calatrava - cuyo papel, en el reinado de Enrique IV, es de inevitable referencia por su peso político. No en vano la intención de Pacheco fue emparentar con la propia familia real a través del matrimonio de su hermano con la infanta Isabel en 1466 afortunadamente no producido por la muerte repentina del maestre.La rama Pacheco, con título de marquesado de Villena, desembocaría, más adelante, en el ducado de Escalona. Por su parte, la rama Téllez Girón, agraciada en la persona del primogénito del maestre Pedro Girón, Alfonso Téllez, con el condado de Urueña, sería distinguida con el ducado de Osuna. El duque de Escalona y el de Osuna, de la Casa de Acuña, como se sabe, ostentaron grandeza de España, ya en el siglo XVI.

\section{El segundo matrimonio de Martín Vázquez de Acuña: el título de conde de Valencia de D. Juan}

Un segundo matrimonio de Martín Vázquez de Acuña con la infanta María de Portugal, condesa de Valencia de Don Juan, permitió la rama de los condes de ese nombre y título del que conviene que nos detengamos. Dicho título tuvo a su primer titular en el infante don Juan afincado en Castilla desde la batalla de Aljubarrota (1385). Don Juan era hijo del rey Don Pedro y de Inés de Castro. Casado en 1377 con María Téllez de Meneses, hermana de la reina de Portugal —Leonor- , Juan fue el primer receptor del título de Duque de Valencia de Campos - transformado en «de Don Juan» a honor a su titular- concedido por Juan I de Castilla en 1387. El ducado caería en desuso hasta que, tiempo después, se volvería a recrear - por poco tiempo- en una cuarta generación en la persona del III conde de Valencia de Don Juan, Gijón y Pravia, durante los años a los que hace referencia

llez Girón, I señor de Belmonte, casado con María Pacheco y padre de Juan Pacheco y Pedro Girón. De la rama o casa de Pacheco, he escrito las siguientes biografias: María Portocarrero, - mujer del marqués de Villena, Juan Pacheco- y cuatro de sus hijos : Diego López Pacheco, II Duque de Escalona, Alonso Téllez, I señor de Montalbán , Beatriz Pacheco, condesa de Medellín, María Pacheco (mujer del conde de Benavente), así como el cardenal Pedro Pacheco y Villena, hijo del I señor de Montalbán, y el I marqués de Villafranca, Luis Pimentel y Pacheco, hijo de los condes de Benavente. De la rama o casa Téllez Girón (hijos de Pedro Girón), he escrito las biografías de los tres primeros condes de Urueña : Alfonso, Juan y Alonso Téllez Girón.Y de la rama Buendía, esto es, los hijos del señor de Buendía, Lope Vázquez, hermano de Martín Vázquez, se han redactado las biografías de dos de sus cuatro hijos: Lope Vázquez de Acuña, I duque de Huete y Gómez Carrillo de Acuña, señor de Jadraque así como la de Inés Herrera, I condesa de Buendía, y de Troilos Carrillo, condestable de Navarra e hijo del arzobispo Alfonso Carrillo, hijo de Lope Vázquez. 
la concesión del título nobiliario del presente trabajo. Los otros hijos de este segundo matrimonio de Martín Vasques -Enrique, Fadrique, Fernando, Luis, Diego..- - jugaron un papel más discreto en el reino castellano, si bien Beatriz, casada con el señor de Luna, madre del I conde del mismo nombre, inició un linaje de gran protagonismo en tierras leonesas y asturianas durante el reinado de Enrique IV-AIfonso XII y los Reyes Católicos.

\section{Lope Vázquez de Acuña y los señoríos de Huete y Buendía}

La rama directamente relacionada con el receptor del título de I conde de Buendía remite al hermano menor de Martín, Lope Vázquez de Acuña, primer señor de Buendía. Casado con Teresa Carrillo de Albornoz, fue el fundador de otro muy importante linaje - el señorío de Buendía - de donde procedería uno de los personajes más sobresalientes de todo el siglo XV: el célebre Alfonso Carrillo de Acuña y Albornoz, arzobispo de Toledo, personaje esencial para nuestro trabajo. Lope Vázquez de Acuña, I señor de Buendía, y Teresa Carrillo de Albornoz, fueron padres de cuatro hijos: Pedro, — protagonista del presente trabajo-, Gómez Carrillo de Acuña, señor de Mandayona, el citado arzobispo de Toledo, Alonso Carrillo y Lope Vázquez de Acuña, titular del señorío de Huete, un impresionante estado en tierras de Cuenca. Esta rama del linaje Acuña, acumularía dos títulos nobiliarios: el de condado de Buendía y el ducado de Huete, este último de efímera existencia al igual que el citado ducado de Valencia de don Juan.

\section{PEDRO DE ACUÑA EN LA GUERRA CIVIL CASTELLANA (1465-68). LA CONCESIÓN DEL TÍTULO DE I CONDE DE BUENDÍA}

\section{El contexto: una dualidad monárquica}

En 1464 estalla en Castilla, la rebelión nobiliaria, larvada en los diez primeros años de reinado de Enrique IV y cuyos antecedentes históricos pueden remontarse a la época de los infantes de Aragón ${ }^{6}$. La gota que colmó el vaso y provocó la insurrección remite a la entrega, por parte rey, del maestrazgo de Santiago al nuevo favorito: Beltrán de la Cueva, algo que, en justicia, sólo le correspondía al entonces infante Alfonso, hijo del segundo matrimonio de Juan II con Isabel de Portugal $^{7}$. De hecho, Enrique IV había incumplido absolutamente todas las claúsulas contenidas en el testamento de su padre con respecto a sus hermanastros -incluyendo a la infanta Isabel-y el maestrazgo de Santiago era una de ellas. Las consecuencias de aquella entrega tenían, además, graves efectos directos al des-

\footnotetext{
${ }^{6}$ Para un conocimiento del problema planteado con los nobles, desde el reinado de Juan II, ver el espléndido trabajo de L. SUÁREZ FERnÁndeZ, Enrique IV de Castilla. La difamación como arma política. Barcelona, Ariel, 2001.

${ }^{7}$ Ver mi «Documentación acerca de la administración de la Orden de Santiago por el príncipe-rey Alfonso de Castilla», Hidalguía, 211 (1988), pp. 839-868.
} 
plazar del poder al todopoderoso Juan Pacheco, un poder del que disfrutaba desde hacía más de veinte años. El resentido marqués de Villena, que codiciaba el maestrazgo de Santiago, se encargó entonces de aglutinar a los distintos grupos políticos nobiliarios profundamente descontentos con Enrique IV encendiendo la rebelión en Castilla con el pretexto del incumplimiento -absolutamente ciertodel testamento de Juan II con respecto a su hijo varón menor. Los conciertos llevados a cabo a finales de 1464 entre Enrique IV y los nobles provocan el reconocimiento, mediante juramento tanto directo como realizado en unas Cortes itinerantes, del pequeño Alfonso - de once años- como príncipe de Castilla y León. Cabe considerar que esa decisión se justificaba por la condición masculina del infante pero, a fin de permitir una salida honrosa al monarca, el príncipe Alfonso se prometía en matrimonio con Juana, la hija del rey, a la que se denomina princesa por imposición de Enrique IV. El monarca creía acallar así el secreto a voces que la consideraba ilegítima o, incluso, adulterina, a la inocente niña de entonces dos años. El príncipe heredero Alfonso, sin embargo, nunca conseguirá el Principado de Asturias que le correspondía, ya que su tutor, el propio marqués de Villena - siempre jugando a dos bandas-le hace negra traición comprometiéndose con Enrique IV para no entregarselo jamás. Pero lo que podría haber quedado en un ajuste de cuentas y un chantaje entre el valido y el monarca se salió de sus cauces. Buena parte de los nobles buscaban la reforma de la monarquía plasmada en la llamada Sentencia de Medina del Campo (febrero de 1465). Su no aceptación por parte del rey provocó la guerra no sin antes producirse un acto, con prácticamente toda la nobleza del reino presente, por el que Enrique IV era derrocado y sustituído por su hermano, el príncipe heredero Alfonso, el 5 de junio de 1465 en Ávila, acto conocido a lo largo de la historia como «La Farsa de Avila».

No puede entenderse el reinado de Alfonso sin hacer referencia a los nobles. Prácticamente la mayoría de los grandes y también de los pequeños linajes se pasaron a la causa del nuevo rey. Alfonso XII gozará del apoyo de los más grandes -Enríquez, Manrique, Stuñiga, Pimentel... - si bien las cabezas visibles de la rebelión remiten al ya citado marqués de Villena, a su pariente el arzobispo de Toledo, Alfonso Carrillo, y al Almirante, Fadrique Enríquez, futuro abuelo de Fernando el Católico. Los dos primeros, representantes del linaje Acuña, demuestran que, desde el punto de vista nobiliario, fue la familia clave que apoyó el cambio de titularidad en la monarquía castellana en 1465.

Durante tres años el reino vive en una dualidad monárquica tan tozuda que su fin sólo se producirá por la muerte de Alfonso XII, muerte sospechosa puesto que sólo con su desaparición física se despejaba la situación política para el factotum del reinado, Juan Pacheco, que meses antes del final, había conseguido del joven rey, el ansiado maestrazgo de Santiago, la clave para entender el comienzo del conflicto en 1464. Durante aquellos tres años de peculiar guerra civil hubo intentos para solucionar la crisis de dualidad monárquica, siendo la más importante la que conducía a una situación en la que Alfonso volviera a su condición de príncipe heredero, esto es, a 1464. Incluso puede demostrarse que el propio joven 
también pudo desear esa solución. Pero el núcleo duro del partido alfonsino se negó en rotundo. La personificación de la negativa remitía a un hombre: el arzobispo Alfonso Carrillo, probablemente el personaje que más apoyó a Alfonso como rey, el que nunca quiso dejarlo a la altura de heredero, el que tolera a Isabel, futura reina católica, sólo por ser su heredera, y el que, en fín, no acepta besar la mano del rey Enrique IV en Guisando hasta que no jurara a la joven como futura reina de Castilla. Alfonso Carrillo es un personaje extraordinario que ha concitado el interés de los historiadores ${ }^{8}$. Además, el arzobispo es el único que mantiene una relación personal con el joven Alfonso del que no sólo recibirá mercedes ${ }^{9}$-destacándose el juro de 650 doblas de oro de la banda castellana confiscadas a los herederos de Álvaro de Luna- sino que será el confidente de los propios temores del rey como se refleja en la magnífica crónica de Alfonso de Palencia, hombre, por otra parte, del Arzobispo. Carrillo, pues, es el hombre clave dentro del reinado de Alfonso habida cuenta que Pacheco, el auténtico artífice de aquella dualidad monárquica, no tenía el más mínimo interés en que el príncipe-rey continuara ejerciendo como tal y sólo lo utilizaba para sus fines. Esto se demuestra a los pocos meses de haber conseguido el ansiado maestrazgo de Santiago, en cómo prepara la retirada y finiquita con Alfonso no sin antes cobrar todo lo que le pudiera corresponder. En este contexto debe entenderse una de las últimas mercedes del rey a Pacheco: un albalá del 14 de mayo por el que manda a sus contadores mayores que paguen al maestre de Santiago los gastos que había hecho desde 1464 yendo de la villa de Madrid a la de Alcalá para liberarle a él y a su hermana, la infanta Isabel, de la opresión en que los tenía la reina doña Juana ${ }^{10}$.

${ }^{8}$ F. Esteve Barba, Alfonso Carrillo de Acuña, autor de la unidad de España, Barcelona, Amaltea, 1943; G. MIRECKI QUINTERO, «Apuntes genealógicos y biográficos de Don Alfonso Carrillo de Acuña, Arzobispo de Toledo", Anales Toledanos, 1991, 28, pp. 55-75; E. COOPER, La Mitra y la roca:intereses de Alfonso Carrillo arzobispo de Toledo, Toledo, Diputación Provincial, 2001. J.M. NiETo SoRIA, «Dos prelados en la encrucijada de un trono: Alfonso Carrillo de Acuña y Pedro González de Mendoza», Torre de los Lujanes, 2004, 54, pp. 49-64.

${ }^{9}$ Las 650 doblas de oro de la banda castellana por juro de heredad confiscadas a los herederos de Álvaro de Luna las recibió el 15 de mayo de 1467, documento inédito transcrito íntegramente en las pp. 1334-37 del volumen documental de mi tesis El reinado de Alfonso XII de Castilla publicada como libro con el título Alfonso de Ávila, rey de Castilla, Ávila, Fundación Gran Duque de Alba, 1988. El 8 de septiembre de 1465, el arzobispo recibía 160.000 maravedís vitalicios que tenía don Pedro, hijo de Dionis de Portugal, por juro de heredad. El 20 de febrero de 1466 obtendrá permiso para tener doce acémilas en su casa o en otro lugar cercano a las fronteras de Aragón y Navarra. También gozaría de las alcaidía de Ávila con 120.000 maravedís de salario -el 13 de agosto de 1466 - y la de Molina desde el 15 de diciembre de 1467 con 200.000 maravedís de salario respectivamente. Finalmente la última merced de 60 000 maravedís de juro de heredad en cualquier renta real que eligiese tiene fecha de 8 de marzo de 1468, cuatro meses antes del fallecimiento del rey. En Op. cit p.292.

${ }^{10}$ El documento, muy explícito, permite seguir los primeros pasos de la rebelión cuando el entonces marqués de Villena "por las cosas que cumplían a mi serviçio público ..ha ayuntado a çiertas gentes de cavallo como de pie, vallesteros, lançeros e lombarderos e espingarderos...cuando fue a vistas con el rey de Portogal a la villa de Calahorra e el dicho maestre se apartó del dicho don Enrrique..con los grandes de mis regnos para procurar la liberación de mi persona e dela ynfante doña Isabel mi muy cara e muy amada hermana que estavamos en poder dela reyna doña Joanna en grand peligro de nuestras vidas y personas.. " el argumento del gran peligro al que estaban expuestos los infantes es utilizado profusa- 


\section{El destinatario: Pedro de Acuña y el señorío de Buendía}

Pedro de Acuña y Albornoz, Il señor de Buendía, era, como se ha visto en las líneas anteriores, primogénito de Lope Vázquez de Acuña, I señor de Buendía, y de su mujer Teresa Carrillo de Albornoz, que constituyeron mayorazgo en él en 1446, incluyendo la villa de Buendía. Los hermanos de Pedro, futuro I conde de Buendía, eran Gómez Carrillo de Acuña, señor de Jadraque, el arzobispo de Toledo, Alonso Carrillo, y Lope Vázquez de Acuña, dueño este último de un imponente señorío conquense: Huete. ${ }^{11}$ Pero, a la altura de 1465 el señor de Jadraque ya había fallecido, muy prematuramente por cierto, pues se produjo antes de 1446, cuando el 3 de agosto sus padres otorgaron testamento y fundaron los dos grandes mayorazgos: el de Buendía y Añazón en el resto de sus hijos ${ }^{12}$. Los tres hermanos Acuña tenían, entre ellos, una espléndida relación como se comprueba no sólo en temas de interés, como los mayorazgos, sino en las más variadas cuestiones cotidianas.

Pedro había comenzado su carrera política como embajador de Juan II ante el rey de Navarra y durante ese reinado desempeñó importantes cargos —adelantado de Cazorla, oficial de Cuchillo, alcalde entregador de la Mesta y cañadas de Castilla, guarda mayor y capitán de la guardia ordinaria del rey...- además de ostentar un importante patrimonio: Mansilla, Rueda, Dueñas, Laguna de Negrillos con su castillo y fortaleza. Casado con Inés de Herrera, hija del mariscal y señor de Ampudia, Pedro García de Herrera y de María de Ayala, señora de Salvatierra, los condes de Buendía tuvieron ocho hijos: Lope, Pedro, Fernando, Luis, Alonso, Teresa, María y Leonor fundando mayorazgo en su primogénito, Lope Vázquez de Acuña, el 9 de febrero de 1475, adelantado mayor de Cazorla por merced de su tío Alfonso Carrillo. Don Lope se casaría con Inés Enriquez —hermana de Juana Enríquez, la madre de Fernando el Católico- por lo que la familia no pudo emparentar de manera más directa con los monarcas.

Cuando estalla la rebelión en Castilla, desde 1464, se producirá una política de atracción de partidarios del nuevo rey que remite al momento en que se produce la

mente por la princesa Isabel más adelante. Sólo dos días después, el 16 de mayo, por otro albalá, Alfonso mandaba a los contadores mayores que pagaran a Juan Pacheco los maravedís de juro y de por vida así como las raciones y quitaciones del año 1468 que estaban asentadas en los libros. Después de liquidar las deudas, el maestre de Santiago sólo tuvo que dar el siguiente caso: liberarse del joven rey, cosa que consiguió dos meses después. Los documentos citados están transcritos en el citado volumen de mi tesis doctoral, pp. 1483-86.

${ }^{11}$ M.C. Quintanilla Raso, La ciudad de Huete y su fortaleza a fines de la Edad Media, Publicaciones de la Excma. Diputación Provincial de Cuenca. Serie Historia, Cuenca, 1991. Ver también J. M. SÁNCHEZ BENITO «El poder en una pequeña ciudad castellana: el ejemplo de Huete en el siglo XV», En la España Medieval,25 (2002), pp. 177-212.

12 Gómez Carrillo de Acuña se había casado con la riquísima María de Castilla, nieta bastarda del rey Pedro I, que le reportó un ascenso social nada desdeñable. El matrimonio tuvo dos hijos, Leonor y Alonso, este último continuador de la línea en Jadraque, Miedes y Mandayona. Este último fue, asimismo, el I señor de Caracena y se casó con la V señora de Pinto, Leonor de Toledo, ostentando el oficio de Guarda Mayor del rey con Enrique IV y Alfonso XII. 
concesión de esta concesión. Pedro, Il señor de Buendía, se encontraba en el epicentro de la rebelión. Su familia era la clave en el sostenimiento de Alfonso particularmente, su pariente Juan Pacheco y su hermano el Arzobispo. Pero también su hermano Lope, futuro I duque de Huete, si bien por poco tiempo, gozaba de una importante presencia en la Corte alfonsina en donde siguió ostentando la importante dignidad de Camarero Mayor de las Armas siendo nombrado asimismo Alcalde de los Fijosdalgos, en 1466, por fallecimiento de su antiguo titular. ${ }^{13}$ Otro caso familiar remite al único Acuña partidario de Enrique IV: Juan de Acuña, otro titular de un ducado de corta duración ${ }^{14}$.

A pesar del protagonismo de sus familiares Pedro se mantuvo en un discreto segundo plano político si bien, como prácticamente todo su linaje, apoyaría la causa del rey Alfonso. Y así él es el único receptor de un título nobiliario - I conde de Buendía- concedido en época del jovencísimo monarca y concedido cuatro días después de ser alzado rey —el 9 de junio de 1465—, según reza el documento, otorgado a petición del Arzobispo de Toledo -(Ver Apéndice Documental).

El condado de Buendía ${ }^{15}$ junto con el Cifuentes, Priego y los marquesados de Cañete y Moya remiten a importantes dominios señoriales en las tierras de los

${ }^{13}$ También recibió del rey Alfonso pequeños juros de heredad a cobrar en cualquier renta del reino, cantidades para lanzas así como raciones y quitaciones varias por los cargos ostentados, caso del de Guarda Mayor. Sin embargo para Lope Vázquez el centro de su interés y batalla fue la ciudad de Huete. Sólo cinco días después de ser nombrado rey, Alfonso le confirmaba en la alcaidía con 60.000 maravedís de salario. Tanto Lope como su hijo del mismo nombre recibieron mercedes del joven rey siendo nombrado su primogénito oficial de cuchillo. También recibió privilegios su sobrino —hijo sacrílego del arzobispo Carrillo- lo que lleva a confusión al coincidir tres personajes con idénticos nombres. Eso no impidió que Huete - ciudad y fortaleza - volviera a la Corona constituyendo un típico ejemplo de plaza estratégica mantenida en rebeldía con una resistencia fuertemente organizada. Lógicamente sin Huete, el título ducal desapareció si bien los Vázquez de Acuña siguieron teniendo intereses en la ciudad

${ }^{14}$ No sabemos si la adhesión a Enrique IV de Juan de Acuña era tan desinteresada o realmente aspiraba a la restauración de la herencia de Alfonso de Trastámara — bastardo de Enrique II — esto es, los territorios asturianos de Gijón, Pravia y el castillo de San Martín. Esto provocó el enfrentamiento del conde de Luna - apoyado por el marqués de Astorga-. Enrique IV premió a su único partidario del linaje Acuña con el condado de Gijón y la Pola de Pravia. En 1465, además, el monarca le superó en un grado el título que sobre su villa de Valencia de Don Juan tenía. Ya no era conde. Ahora era el I duque de Valencia de Don Juan. Cuando se produce el acto de Guisando e Isabel es nombrada princesa de Asturias, el ducado queda vacio de contenido por ello, el 15 de noviembre de 1468, desde Colmenar de Oreja, Enrique IV revocaba y anulaba la merced de las villas de Pravia y Gijón hecha a Juan de Acuña. Cuando poco tiempo después el monarca despojaba a su hermana de su condición de heredera volviendo a reconocer a su hija, Juan de Acuña no dudó en apoyar a la pequeña Juana. Así cuando estalló la guerra de sucesión, Juan de Acuña se alió con los partidarios de doña Juana, particularmente con su sobrino, el II marqués de Villena, Diego López Pacheco. Esto le hizo caer en desgracia y suele afirmarse que el título y dignidad de Ducado, por segunda vez —antes lo había ostentado su bisabuelo el infante Don Juan de Portugal- y ya de forma definitiva, se extinguió en su persona no perpetuándose en sus sucesores.

15 J.I.Ortega Cervigón, «Títulos, señoríos y poder: los grandes estados señoriales en la Castilla centro-oriental» en C. Quintanilla, op. cit, pp. 267-307. También, citado en el trabajo por el autor, «El arraigo de los linajes portugueses en la Castilla bajomedieval: el caso de los Acuña en el obispado de Cuenca», en La Península Ibérica entre el Mediterráneo y el Atlántico. s. XIII-XV, Cádiz, 2003 (en pren- 
obispados de Siguenza y de Cuenca —además del ducado del Infantado— todos ellos caracterizados por desempeñar sus titulares oficios cortesanos y ser agraciados con un título nobiliario. El título contiene todos los requisitos propios del acto - perpetuidad, transmisibilidad, irrevocabilidad, gratuidad.. - pero hay una cuestión particular que remite al contexto en que se ha producido la merced y esto es la influencia del hermano del beneficiado: el arzobispo de Toledo, Alfonso Carrillo. Es muy probable que esa concesión se realizara dentro de la política de atracción de partidarios pero también en remuneración por los grandes servicios prestados a la causa alfonsina por el linaje Acuña personificado en la persona del tantas veces mencionado Carrillo. Sin olvidar, como reza el documento, la también remuneración por los servicios prestados por Pedro de Acuña al padre del rey, Juan II, del que el señor de Buendía había sido fiel servidor. En definitiva, era un reconocimiento de servicios que «.. a mí aveis fecho y espero que me fareis e porque me lo suplicó el muy reverendo padre en xpto. don Alfonso Carrillo arzobispo de Toledo primado de las Españas chanceller mayor de Castilla"

Debemos reflexionar sobre la importancia de la categoría nobiliaria del título en sí, esto es, el de conde. Dentro de la jerarquía de los títulos nobiliarios la dignidad de conde, segundo de más importancia tras el marqués, destaca por la cercanía a la figura del gobernante cuya presencia continuada en palacio remite a servicios regios, así como a la capacidad de gobierno de territorios. Mientras que los marqueses tendrían una procedencia original franca y palatina y los duques remitían a un pasado militar romano, los condes enlazan con una dimensión doble: palatina como los marqueses y militar como los duques aunque en menor medida. En el caso hispano los condes, cuya prelación va por detrás de los anteriores, será con la dinastía de los Trastámara cuando los monarcas optan por conceder este tipo de título de forma preferente de nobleza titulada dentro del marco de relaciones entre nobleza y monarquía en reconocimiento y premio a la colaboración prestada y siempre por la proximidad cotidiana. En este tercer nivel de la nobleza titulada, el conde, aun cuando su posición es inferior con respecto al título de marqués, se puede establecer una excepción en caso de que el título correspondiese a un linaje superior por origen o estado según el tratadista Diego de Valera. Como ya se ha subrayado, la concesión de títulos nobiliarios remite al proceso de señorializacion de los territorios castellanos dando lugar a un reforzamiento de los nobles. El título nobiliario corrobora este proceso en la villa más representativa - como se ha observado el título de concede sobre los señoríos ya poseídos- de manera que los títulos ya no eran simples adornos: su transmisibilidad por vía de herencia exhibía la dimensión señorial de sus beneficiarios siendo el símbolo de la importancia de ese noble en la vida política del reino. La nobleza de título —que a

sa). Las villas de Buendía -la única que permaneció vinculada al linaje durante largo tiempo - y Añazon habían sido entregadas por Enrique III a Lope Vázquez de Acuña en 1397 como reconocimiento a su apoyo militar en la lucha contra los musulamanes en Setenil, Ronda y Antequera. Desde entonces Buendía y su tierra fueron el principal dominio señorial de la casa de Acuña en el obispado de Cuenca. 
finales del siglo XV remitía a cinco vizcondados, cincuenta y cuatro condados, quince marquesados y once ducados en el reino castellano- era una demostración de la pertenencia a la elite de poder ${ }^{16}$. En este sentido en el reinado de Alfonso XII se ratificó la importancia del linaje Acuña en la única rama - la de Lope Vasquesque no había sido agraciada con un título ya que sus parientes Pacheco-Téllez Girón y Acuña tenían un marquesado y un condado, y la otra rama de Acuña eran los condes de Valencia de Don Juan.

No obstante, resulta curioso confirmar que el conde de Buendía no volvió a recibir ni una merced más de don Alfonso pero sí fue receptora su mujer, la condesa Inés Buendía que gozó de mercedes varias ${ }^{17}$. En aquellos tres años, el receptor del único título de nobleza expedido por el rey Alfonso, mantuvo una posición de gran discreción para, más adelante, seguir la opción del princesa Isabel, futura reina. Es por ello que, en el comienzo de su reinado, los monarcas le confirmarían el título.

\section{EPÍLOGO}

El rey Alfonso XII fallece en Cardeñosa (Ávila), probablemente envenenado por Pacheco, el 5 de julio de 1468. Con su muerte se producía el fin de la dualidad monárquica y la reconciliación política del antiguo valido con Enrique IV. Pero no se logra la vuelta a la paz en el reino. Esto último resultará imposible porque la heredera de Alfonso, la futura reina católica, se presentará como su continuadora, como se comprueba en la documentación expedida poco después de la muerte de su hermano y verificable en las vistas de Guisando adonde llegará Isabel como la candidata del partido alfonsino. La infanta, no obstante, adoptará inteligentemente la postura de declararse doble heredera legítima, a título de princesa, de Alfonso y, como futura reina, por parte del propio Enrique. Heredera de sus dos hermanos, no podrá disimular su gran admiración por el hermano fallecido prematuramente como se comprueba en muchos de sus actos. Para ella, sólo hay un hermano y un rey: Alfonso. De hecho ya había elegido entre ambos. Cuando se produce la toma de Segovia en 1467 Isabel decide abandonar la Corte de Enrique IV y se marcha feliz con su hermano pequeño hasta el fallecimiento de aquel. Si consideraba que se trataba de un rebelde ¿porqué se marcha con él? ¿porque no demuestra que apoya al legítimo rey quedándose en Segovia? De él herederá, pues,

\footnotetext{
${ }^{16}$ C. Quintanilla, op. cit, p. 49 y ss.

${ }^{17}$ Inés de Herrera fue receptora de varias mercedes en diversos lugares de la zona: merindad de Cerrato, en Palencia, sobre la villa de Baltanás se le habían situado y puesto por salvado seis mil maravedís renunciados por Juan de Guevara el 25 de septiembre de 1465. El 20 de enero de ese año se le concedieron las tercias de Baltanás que, como en los casos de Villabrales y Castromocho, debieron de tardar en llegar a manos de la condesa — la beneficiaria no había podido sacar la carta de privilegio- ya que el rey, unos meses después, se dirigió a las autoridades de la villa para se cumpliera su mandato. D.C. Morales Muñiz, «El primer Alfonso XII y Palencia». Actas del I Congreso de Historia de Palencia. Tomo II. Diputación Provincial de Palencia, 1986 pp.527-37;
} 
la sucesión del reino y así se lo hace saber a varias ciudades a través del secretario favorito de Alfonso, Juan Fernández de Hermosilla, a las pocas horas de morir su hermano. Las actuaciones posteriores de Isabel demuestran que no desautoriza a Alfonso XII. Esto se comprueba en la documentación en donde denomina a su hermano rey durante más de doce años si bien, a partir de 1480 , para reforzar su propia legitimidad y que no se le asociara con un acto de rebeldia, la reina sólo se referirá a su hermano fallecido como príncipe. ${ }^{18}$

La concesión del título de conde de Buendía se inscribe, dentro del reinado de Alfonso XII, en un acto que quiere demostrar el ejercicio del poder monárquico y la existencia de una realidad que aspira a la continuidad y a la permanencia: una Corte plenamente desarrollado, una sólida administración, una cancillería efervescente y unos órganos de gobierno que permiten actos tan soberanos como el de acuñar moneda, la continuidad documental en los registros del sello o la expedición de títulos nobiliarios. El hecho de que, más adelante, la reina Isabel confirmara ese último acto como otros tantos que él había llevado a cabo, no hace sino ratificar la condición de su hermano Alfonso como el legítimo rey de Castilla.

\section{APÉNDICE DOCUMENTAL}

\section{5, 9 de junio. Real, cerca de Arévalo}

\section{Cédula del rey Alfonso por la que concede el título de conde de Buendía a Pedro de Acuña}

Real Academia de la Historia., M-92, hojas 266 a. y r.

Don Alfonso por la graçia de Dios, rey de Castilla, León, de Toledo, de Galisia, de Sevilla, de Cordova, de Murçia, de Jahén, del Algarbe, de Algesira, de Gibraltar e señor de Viscaya e de Molina acatando la persona e linaje de vos, Pedro de Acuña, mi vasallo e del mi consejo y queriendo honrrar y sublimar e asimismo acatando los muchos y grandes y señalados servicios que al rey don Johan de gloriosa memoria mi señor padre, que aya santa gloria, y a mí aveis fecho y espero que me fareis e porque me lo suplicó el muy reverendo padre en Xpto don Alfonso Carrillo, arzobispo de Toledo, primado de las Españas, chanceller mayor de Castilla, por la presente vos fago conde de la vuestra villa de Buendía e quiero y es mi merced que vos podades llamar y nombrar y podedes y llamedes y nombredes de aqui adelante, don Pedro de Acuña, conde de Buendía, e por este mismo título se pueda nombrar e nombre vuestro fijo lexitimo y la persona o per-

\footnotetext{
${ }^{18} \mathrm{He}$ reflexionado varias veces sobre la herencia de su hermano menor en ella y cada vez me reitero más: a Isabel la traicionan sus actos, sus gestos y sus símbolos — política monetaria, el impresionante enterramiento de rey que le dispensa a su hermano, en los colaboradores de Alfonso que conserva, en la miniatura del Libro de Horas que ella continua, en la Corte literaria que luego mantuvo...-. Alfonso vivió en el legado de Isabel como he defendido en no pocas ocasiones y particularmente en las últimas publicaciones citadas en la nota 1.
} 
sonas que ovieren de heredar y heredasen vuestra casa e que vos sean fechas y guardadas todas las ceremonias y honores que son fechos y se acostumbran faser a los otros condes de mis regnos e por esta mi carta mando a los duques, condes, marqueses, ricos ommes, maestres de las ordenes, priores y a los del mi consejo y oidores dela mi abdiencia y alcaldes y notarios y alguacil y otras justicias y oficiales quualesquier de la mi casa y corte y chancillería y a los comendadores, subcomendadores, alcaides de los castillos y casas fuertes y llanas y a otros qualesquier mis vasallos y súbditos y naturales de cualquier estado o condición preheminencia o dignidad que sean y a cada uno delos que de aqui adelante vos tennga y nombren y llamen e intitulen Don Pedro de Acuña Conde de Buendia. E por ese mismo título al que asi oviere de aver y heredar la dicha vuestra casa e vos guarden e fagan guardar todas las preheminencias, prerogativas, ynmunidades que vos deben ser guardadas por rason del dicho título segund son guardadas a cada vos de los otros dichos condes de mis regnos. Ca yo por la presente como dicho es vos do el dicho título de conde de Buendía e después de vos a la persona o personas que así ovieren de heredar y heredaren la dicha vuestra casa. e los unos etc.

De lo qual vos mandé dar esta mi carta firmada de mi nombre e sellada con mi sello. Dada en el real cerca de Arevalo a nueve dias del mes de junio año del nascimiento de Nuestro Señor Jhesucristo de mil e quatrocientos e sesenta e cinco años. Yo el Rey. 